

\title{
Glass integrated optic waveguides combining optical grade dicing and ion-exchanged planar waveguide
}

Alain Morand, Yashpreet Kaur, Martine Gri, Gustavo Ardila, Pierre Benech

\section{To cite this version:}

Alain Morand, Yashpreet Kaur, Martine Gri, Gustavo Ardila, Pierre Benech. Glass integrated optic waveguides combining optical grade dicing and ion-exchanged planar waveguide. SPIE OPTO, Feb 2019, San Francisco, United States. pp.17, 10.1117/12.2507530 . hal-02066613

\section{HAL Id: hal-02066613 \\ https://hal.univ-grenoble-alpes.fr/hal-02066613}

Submitted on 11 Oct 2019

HAL is a multi-disciplinary open access archive for the deposit and dissemination of scientific research documents, whether they are published or not. The documents may come from teaching and research institutions in France or abroad, or from public or private research centers.
L'archive ouverte pluridisciplinaire HAL, est destinée au dépôt et à la diffusion de documents scientifiques de niveau recherche, publiés ou non, émanant des établissements d'enseignement et de recherche français ou étrangers, des laboratoires publics ou privés. 


\section{Glass integrated optic waveguides combining optical grade dicing and ion-exchanged planar waveguide}

A. Morand, Y. Kaur, M. Gri, G. Ardila, P. Benech

A. Morand, Y. Kaur, M. Gri, G. Ardila, P. Benech, "Glass integrated optic waveguides combining optical grade dicing and ion-exchanged planar waveguide ," Proc. SPIE 10921, Integrated Optics: Devices, Materials, and Technologies XXIII, 109210I (4 March 2019); doi: 10.1117/12.2507530 


\title{
Glass integrated optic waveguides combining optical grade dicing and ion exchanged planar waveguide
}

\author{
A. Morand, Y. Kaur, M. Gri, G. Ardila, and P. Benech \\ Univ. Grenoble Alpes, CNRS, Grenoble INP*, IMEP-LAHC, 3 Parvis Louis Neel, \\ F-38000Grenoble, France \\ * Institute of Engineering Univ. Grenoble Alpes
}

\begin{abstract}
Due to small refractive change, it is difficult to obtain high confined glass integrated waveguide. A proposed solution is to make firstly a planar waveguide by ion exchanged and then to use an optical grade dicing to realize two separated grooves. The cutting and the polishing of the glass are made at the same time. Monomode ridge waveguide with a smallest width of $4 \mu \mathrm{m}$ and a height of tens micrometers are characterized, either in the near-infrared domain or in the visible domain. The propagation losses can be smaller than $1 \mathrm{~dB} / \mathrm{cm}$ with fiber coupling losses around $2 \mathrm{~dB}$ depending on the fiber used to excite the waveguide.
\end{abstract}

Keywords: Integrated optics, Glass waveguides

\section{INTRODUCTION}

The glass ion exchanged integrated optic is a mature technology showing high potentiality these last twenty years. Indeed, it allows the realization of several type of sensors or devices. ${ }^{1-6}$ Few of them remain at the research and development level but others have been directly used to realize industrial devices by different companies as LEONI Fiber Optics (LFO), ${ }^{7}$ Teem Photonics, ${ }^{8}$ the company IOT $^{9}$ or Corning. ${ }^{10}$ By now, these devices are based on planar light waveguides (surface waveguides or buried waveguides) using a lateral spatial confinement with a refractive index contrast maximum from 0.01 to $0.1{ }^{11}$ Several optical functions can be limited by this feature. Indeed, the ion exchanged $\mathrm{K}^{+} / \mathrm{Na}^{+}$is characterized by a refractive index contrast close to 0.01 which can be used to propagate light in the visible and the near infrared wavelength range. Nevertheless, the waveguides realized are large compared to the wavelength used. In this paper, we propose a method to reduce this width on straight waveguide based on optical grade dicing. It has been already used on Niobate Lithium substrate with encouraging results. ${ }^{12-14}$ Other goups apply this technology to obtain waveguides in nonlinear material. ${ }^{15,16}$

\section{WAVEGUIDE SHAPE AND MODELIZATION}

The solution proposed in this paper is based firstly on the realization of a planar waveguide by thermal ion exchanged $\mathrm{K}^{+} / \mathrm{Na}^{+}$in a borosilicate glass. The planar waveguide obtained has a gradient refractive index profile which can be estimated by a function which is an error complementary function:

$$
\begin{array}{ll}
x>0 & n(x)=1 \\
x \leq<0 & n(x)=n_{s}+f(x) \\
& f(x)=\Delta n \cdot \operatorname{erfc}(-x / 2 \sqrt{D . t})
\end{array}
$$

$\Delta n$ is the refractive index contrast at the surface $x=0$ and $D$ is the diffusion constant. For soda lime wafer glass, $\Delta n$ and $D$ are close respectively to $10^{-3}$ and $0.03 \mathrm{\mu m}^{2} / \mathrm{min}$. This process defined the vertical confinement. Secondly without using a photolithography process in a clean room, two rectangular grooves are realized all along the waveguide propagation axis and the separation between the slots defines the waveguide width as shown in the figure 1a). These grooves are realized with a circular precision saw to obtain a small roughness of the vertical

Further author information: (Send correspondence to A. Morand)

A. Morand: E-mail: alain.morand@univ-grenoble-alpes.fr, Telephone: +33456529486

Integrated Optics: Devices, Materials, and Technologies XXIII, edited by Sonia M. García-Blanco, Pavel Cheben, Proc. of SPIE Vol. 10921, 109210I - @ 2019 SPIE - CCC code: 0277-786X/19/\$18 - doi: 10.1117/12.2507530 


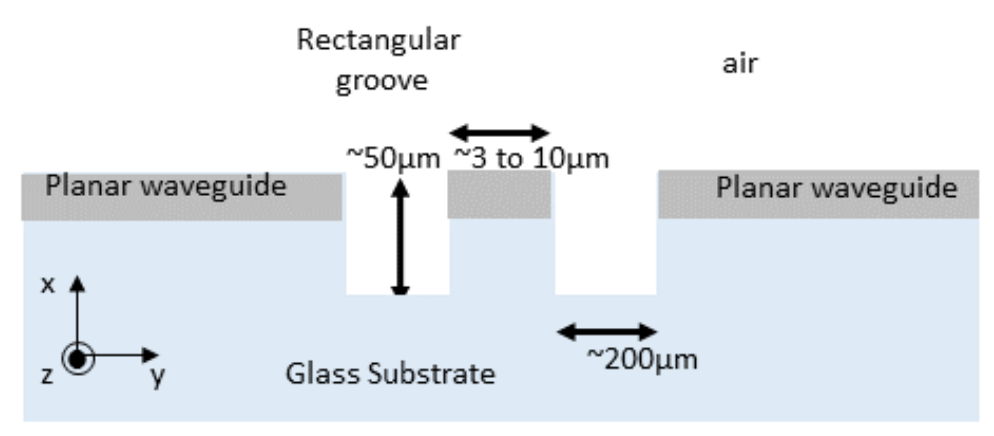

(a)

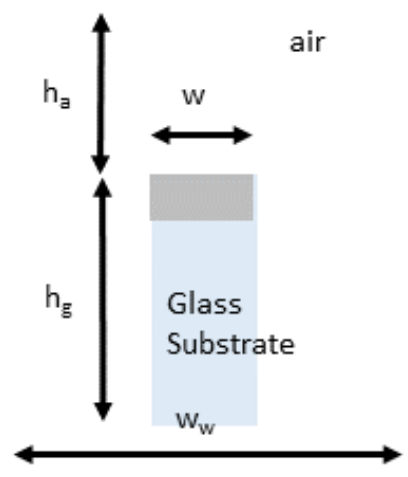

(b)

Figure 1. (a) Cross sectional view of the ridge waveguide studied issued from a saw dicing at each side of the waveguide. (b) Cross section view of the waveguide structure modelized with AFMM.
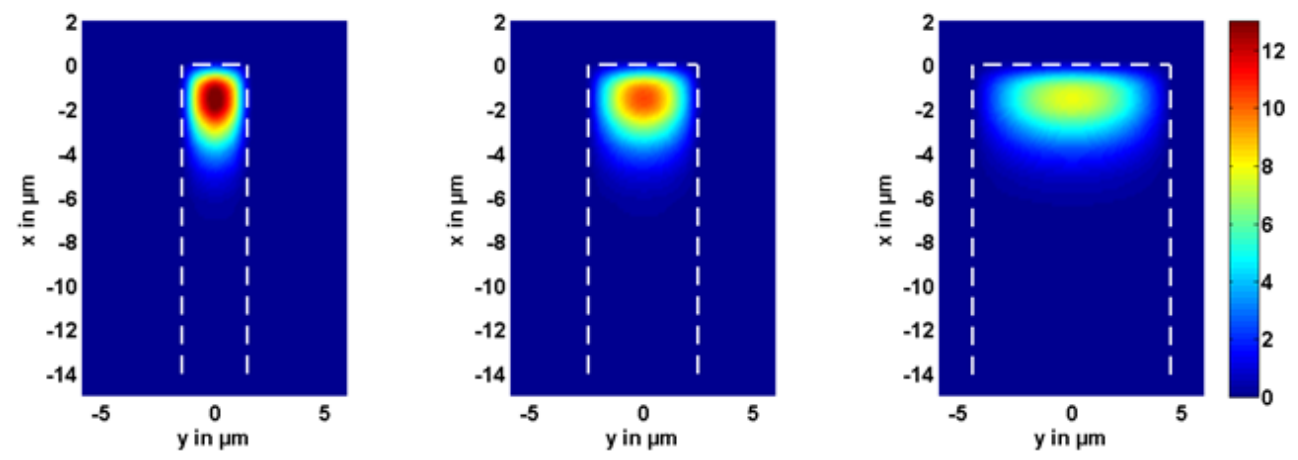

Figure 2. Examples of waveguide mode profiles modelized with the AFMM (51 harmonics for $x$ and $y$ axis). The magnitude of $E_{y}$ field (TE mode) with respectively the width $3 \mu \mathrm{m}$ (a), $5 \mu \mathrm{m}$ (b) and $9 \mu \mathrm{m}$ (c). The diffusion constant and the refractive contrast are respectively $D=0.027 \mathrm{\mu m}^{2} / \mathrm{min}$ and $\Delta n=0.016$. The time exchanged is $t=4 \mathrm{~h}$. The optical wavelength is $800 \mathrm{~nm}$.

faces. The depth of the groove is chosen higher than the size of the mode in the vertical axis. As the width of the saw is higher than $100 \mu \mathrm{m}$, the window simulation used to modelize the modes propagating in this kind of waveguide is simplified by the model shown in the figure $1 \mathrm{~b}$ ).

The Aperiodic Fourier Modal Method (AFMM) ${ }^{17,18}$ is used to modelize the modes which can be guided in this structure. The window size $w_{w}$ used in the simulation is a width of $w_{w}=20 \mu \mathrm{m}$ and an height of $h=30$ $\mu \mathrm{m}$ in the y direction. This height is decomposed of a glass part height $h_{g}=25 \mu \mathrm{m}$ and air part height $h_{a}=5$ $\mu \mathrm{m}$. The width of the waveguide is defined by $w .51$ harmonics are used in the $y$ and $x$ axis to simulate the waveguide. An example of modes for different structure are shown in figure 2 . The effect of the waveguide width is observed on the fundamental mode. The mode obtained for $w=3 \mu \mathrm{m}$ with the ridge structure has an elliptical shape due to the refractive contrast which is different between the $\mathrm{x}$ axis and $\mathrm{y}$ axis. The field extends vertically when the waveguide width decreases. This asymetric shape can be characterized by astigmatism effect.

Before realizing the structure, simulations have been made to study the monomodicity of this kind of waveguide following the time of the ion-echanged $t$ and the surface refractive contrast $\Delta n$. The diffusion constant $D$ is considered constant and well defined. This is not the case for the refractive contrast $\Delta n$ which can change with the time of the ion-exchanged process. ${ }^{20}$ The results are shown in figure 3.31 harmonics are used in the $y$ and $x$ axis to simulate the waveguide. To work in the NIR, a time exchange $t=8 \mathrm{~h}$ with a width $w=9 \mu \mathrm{m}$ is a good couple in order to have a monomode waveguide from $1250 \mathrm{~nm}$ to $1800 \mathrm{~nm}$. To work in the visible domain, the 


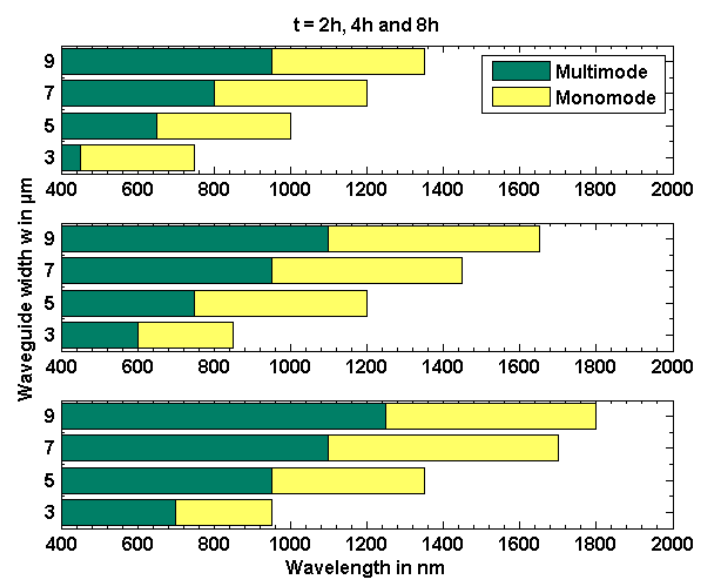

Figure 3. Evolution of the monomodicity zone following the ion-exchanged time and the waveguide width. The diffusion constant and the refractive contrast are respectively $D=0.027 \mathrm{\mu m}^{2} / \mathrm{min}, \Delta n=0.016$ and the glass refractive index considered constant $n_{s}=1.4970$.

monomodicity will be narrower and a choice of couple can be a time exchange $t=2 \mathrm{~h}$ with a width $w=3 \mu \mathrm{m}$ in order to have a monomode bandwidth from 450 to $750 \mathrm{~nm}$. These parameters are crucial and must be reach by the technological process shown in the next section.

\section{WAVEGUIDE REALIZATION}

For the realization of the planar waveguide, the glass chip is set in a $\mathrm{KNO}_{3}$ molten salt at a temperature of $380{ }^{\circ} \mathrm{C}$ during a time $t=2,4$ or $8 \mathrm{~h}$. The diffusion constant is estimated to be $D=0.027 \mathrm{\mu m}^{2} / \mathrm{min}$ with a refractive difference at the surface of $\Delta n=0.016$. The glass wafer is a soda lime glass. The rectangular groove is realized in a second step by optical grade dicing with a circular precision saw (DISCO DAD321). To obtain a vertical surface with the minimum roughness, a blade is specially chosen. In our case, the blade used is from the family P1A from DISCO. The external and the internal diameters are respectively $55 \mathrm{~mm}$ and $40 \mathrm{~mm}$ used with a flange diameter of $53.5 \mathrm{~mm}$ which allow a maximum depth dicing of $750 \mu \mathrm{m}$. The blade thickness is $200 \mu \mathrm{m}$. The diamond particles are bonded in a resin on the blade. The particle size is chosen at the minimum size that can be provided by the manufacturer $(<2 \mu \mathrm{m})$ with a concentration close to $25 \%$. This concentration begins to be important for the manufacturer but higher is the concentration and less the blade wear. Rotation speed and translation speed of the blade are respectively $10000 \mathrm{rpm}$ and $0.2 \mathrm{~mm} / \mathrm{s}$ which are the couple values used for lithium niobate substrate. ${ }^{12}$ This allows both the dicing and the polishing of the vertical surfaces. The feed rate, the distance travelled by the blade in one revolution, is $1.2 \mu \mathrm{m} /$ rev. For a Flame Hydrolysis Deposition (FHD) silica deposition in Silicon this feed rate higher than $0.4 \mu \mathrm{m} / \mathrm{rev}$ doesn't reach the ductile dicing regime. The diamonds are also bonded in a nickel on the blade. ${ }^{19}$ So it minds that the polishing could be eventually improved if the soda-lime glass used has the same proprieties of the FHD. During the dicing process, the blade is cooled with water to control the temperature and eliminate the diamond and glass particles. Finally, the vertical position of the blade is set to have a depth of the groove around $50 \mu \mathrm{m}$. This depth is chosen to be higher than the vertical mode profile size of few micrometers. The displacement of the blade on the plan $(\mathrm{y}, \mathrm{z})$ is accurate at the micrometer. Whereas the real depth obtained compared to the depth set in the equipment is less accurate. This depth depends on different features: the planarity and the thickness of the glass wafer, the thickness of the film layer used to set the sample in the equipment and the blade wear after each cut. By now this depth is accurate at $10 \mu \mathrm{m}$. So two cuts are necessary to obtain a waveguide. The second cut is made after a displacement of the blade in the y axis of the width of the blade and the width of the waveguide to realize. Then, in order to be able to couple light coming from a fiber in the waveguide or to analyse the intensity signal radiated from the output waveguide, it is necessary to cut and polish the input and output facets. The same blade is used to do these cuts. The depth of the cut is in this case is deeper in order to be able to approach a fiber with a diameter of $125 \mu \mathrm{m}$ close to the facet. Few cutting can be necessary at the same position to obtain 

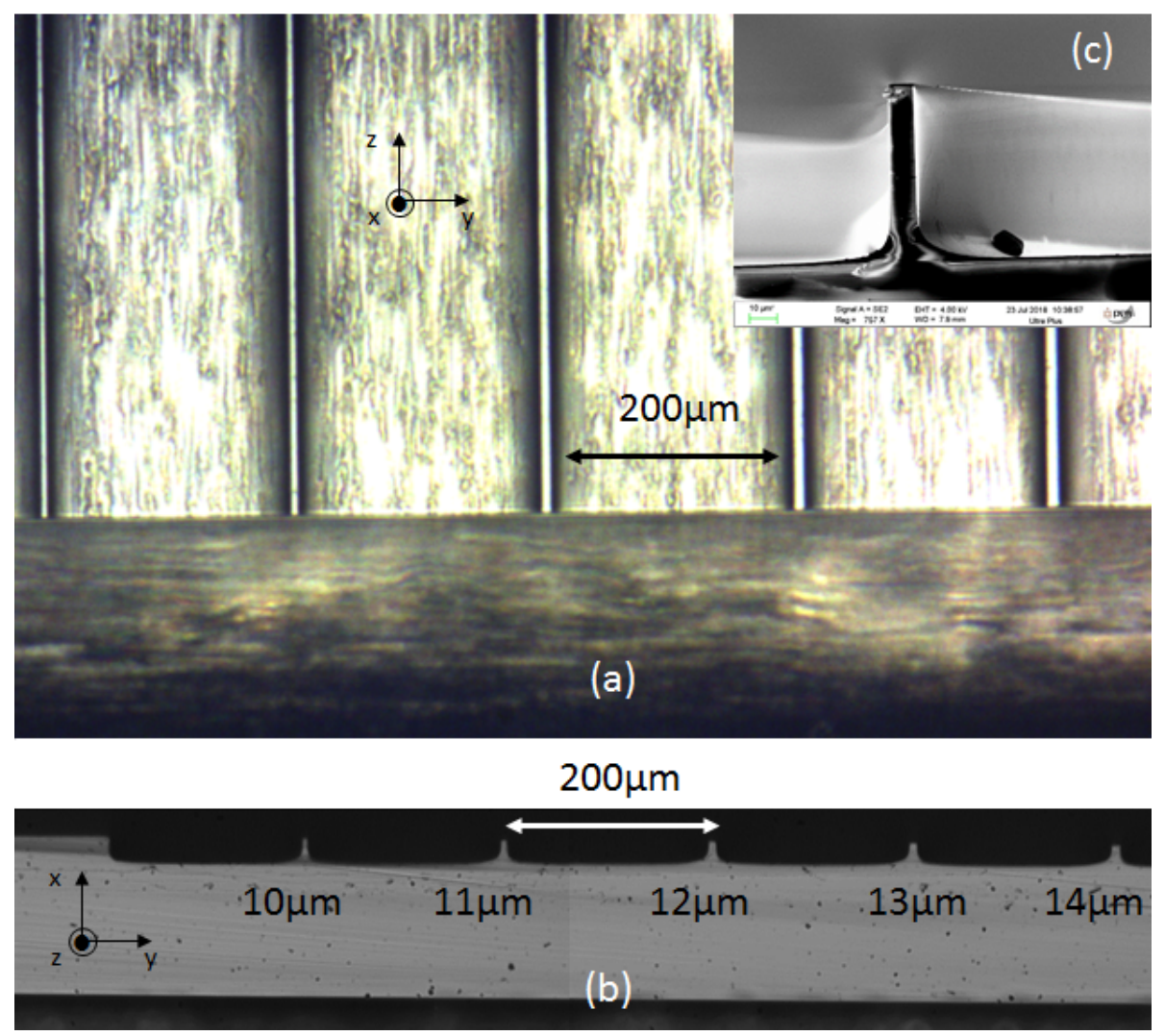

Figure 4. a) optical top view the sample. b) optical cross sectional view of the sample. c) SEM view of the sample. This sample is a glass wafer soda lime with a time exchange $t=8 \mathrm{~h}$.

the sufficient depth. As the glass wafer thickness is large compared to the potentiality of the blade cut depth, a secondary blade is used with higher roughness which can reach a depth of $0.75 \mathrm{~mm}$ allowing us then to cleave the sample with a thickness of $1 \mathrm{~mm}$. The blade for this cut is slightly shift in the $\mathrm{z}$ axis in order to not touch the previous polished facet.

Some results after the cut can be observed in figure $4 \mathrm{a})$. In figure $4 \mathrm{~b}$ ), the depth cut and polished by the blade with the smallest roughness is the zone in grey. The colour is very homogeneous and it is related to the good polishing of the blade. The black zone under is a feature of the second blade not well focused on this image. The width increase prove the control of the blade displacement. The waveguides keep their width along the $\mathrm{z}$ axis as shown in the figure $4 \mathrm{a})$. The blade is not strictly rectangular. The corners are slightly rounded which are characterized by the black shallow around the waveguides. In order to avoid this zone a minimum depth of 10 $\mu \mathrm{m}$ must be reached. In the figure 4c), an image of a waveguide has been obtained by a SEM (Scanning Electron Microscope) after depositing a thin layer of gold on the surface of the glass. A very smooth surface at each side of the waveguides can be observed.

Different series of waveguides have been realized with an initial width coming from 10 to $14 \mu \mathrm{m}$. Three different exchanged times $t$ have been tested $8 \mathrm{~h}, 4 \mathrm{~h}$ and $2 \mathrm{~h}$. Different characterizations have been done to analyse these waveguides described in the next section.

\section{WAVEGUIDE CHARACTERIZATION}

Each waveguide realized has been analysed with the following measurements: the waveguide width has been measured to estimate the effect of the roughness of the blade thanks by an optical microscope. The profile of radiated intensity of the waveguide has been measured for different wavelengths. A spectral set-up measurement 


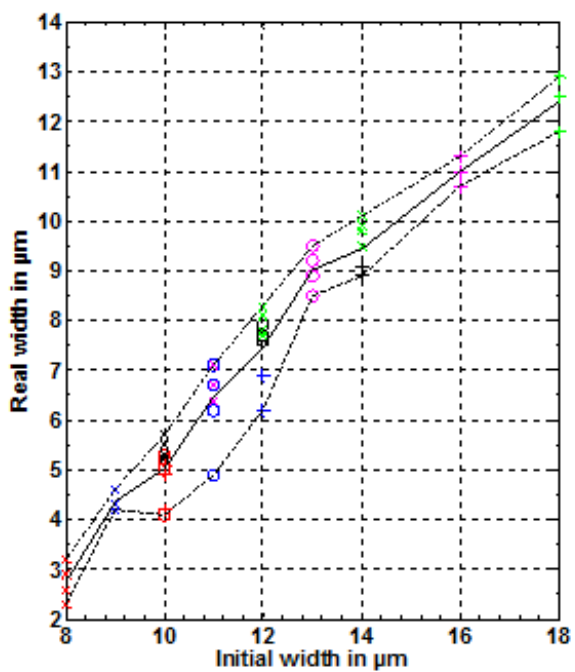

a)

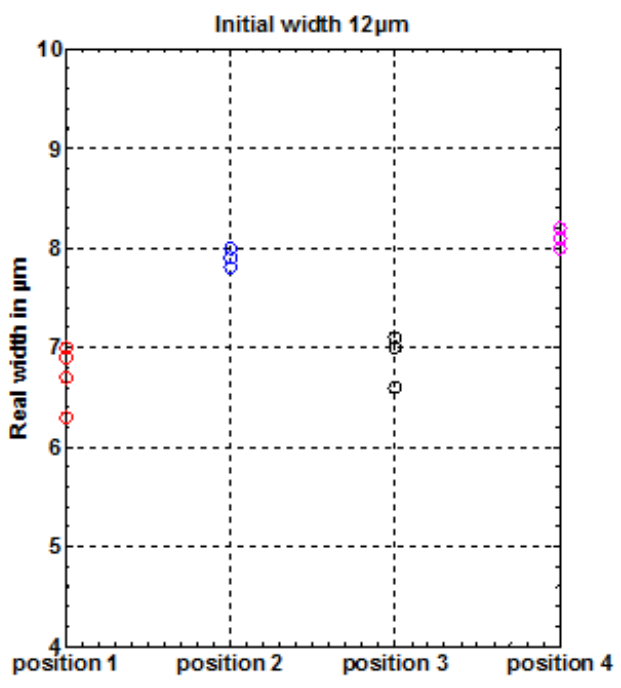

b)

Figure 5. a) evolution of the real width of the waveguide compared to the initial value (o, $\mathrm{x}:$ respectively $8 \mathrm{~h}$ and $4 \mathrm{~h}$ in a soda lime, +: $72 \mathrm{~h}$ in borosilicate glass, -: mean value, - -: minimum value and -.-: maximum value). b) evolution of the real width of the waveguide for the same initial value but at different position along the $\mathrm{z}$ axis.

associated to the analysis of the output mode is used to measure the monomodicty bandwidth. And finally, insertion losses have been measured from the fiber-sample-fiber configuration and the fiber-fiber one.

In the figure 5a), it can be observed the evolution of the width of all the waveguides realized on different substrates. Following the substrate, the time exchanged is different or the glass can be a borosilicate glass instead of the soda lime glass. But at the first order, we consider that the mechanical effect is not sensitive to these differences. Firstly, the real width is always smaller than the initial value. This decrease seems to be constant close to $4.5 \pm 1 \mu \mathrm{m}$. This is the effect of the roughness of the blade increasing its width during the cut. For an initial width higher than $13 \mu \mathrm{m}$, this decrease is the highest and close to $5 \pm 0.5 \mu \mathrm{m}$. The minimum width is $2.3 \mu \mathrm{m}$. Due to the variation of the width, it is very difficult to obtain a smaller value. Moreover, for small width, the height of the ridge is crucial. And it must be small tens micrometers in order to have a waveguide not broken all along the $\mathrm{z}$ axis. In the figure $5 \mathrm{~b}$ ), it is shown the evolution of the width following the position measurement along the $\mathrm{z}$ axis for four waveguides realized on the same substrate with the same initial width. The ratio between the initial and real width value is the same as seen previously. But we can observe an evolution of the width following the position $i$ related to $z_{i}$ (with $z_{4}>z_{3}>z_{2}>z_{1}$ ). This evolution is followed in the same way by all the waveguides. So this phenomena seems to be independent of the blade wear. Perhaps, it is an effect of the glass wafer (Glass density or depth of the blade in the glass ...). As this variation is low compared to the optical wavelength, the power transmission can be considered adiabatic. But the spectral transmission could be sensitive to a decrease of the width during the propagation and specially if the optical wavelength used is close to the cut-off wavelength.

Some intensity maps are shown in the figure 6. Four figures are the fundamental intensity modes of few waveguide widths set initially to $11 \mu \mathrm{m}, 12 \mu \mathrm{m}, 13 \mu \mathrm{m}$ and $14 \mu \mathrm{m}$. The glass wafer is a soda lime and the measurement has been made with an optical source at the wavelegnth $\lambda=1550 \mathrm{~nm}$. The decrease of the mode width is clearly observed. The last figure is the smallest mode measured with a real waveguide width close to 3 $\mu \mathrm{m}$. This waveguide is monomode for the wavelength $0.635 \mu \mathrm{m}$. The evolution is similar to the evolution shown previously in the waveguide shape and modelization section.

The monomodicity bandwidth of each waveguide has then been analysed. For that a white optical source connected to a multimode fiber is used to excite the waveguide. And the signal at the output waveguide is coupled in a second multimode fiber connected to an optical spectrum. The wavelength range analysed is from 

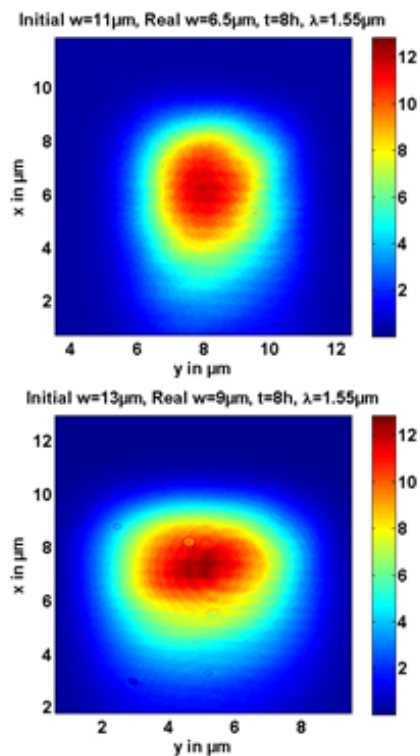


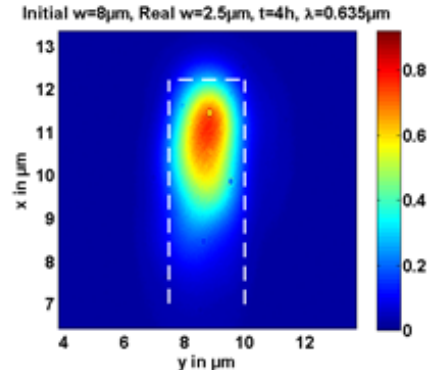

Figure 6. Examples of waveguide mode profiles measured. The initial waveguide width of the two first columns are 11 $\mu \mathrm{m}, 12 \mu \mathrm{m}, 13 \mu \mathrm{m}$ and $14 \mu \mathrm{m}$. The glass wafer is a soda lime and the measurement has been made with an optical source at $\lambda=1550 \mathrm{~nm}$. The objective lens is a Mitutoyo lens $\times 100$ and the camera is a sensor goodrich NIR $256 \times 320$ pixels. The time exchanged is $t=8 \mathrm{~h}$. In the last column, the initial waveguide width is $8 \mathrm{\mu m}$, the time exchanged $t=4 \mathrm{~h}$ and an optical source at $\lambda=635 \mathrm{~nm}$ is used.
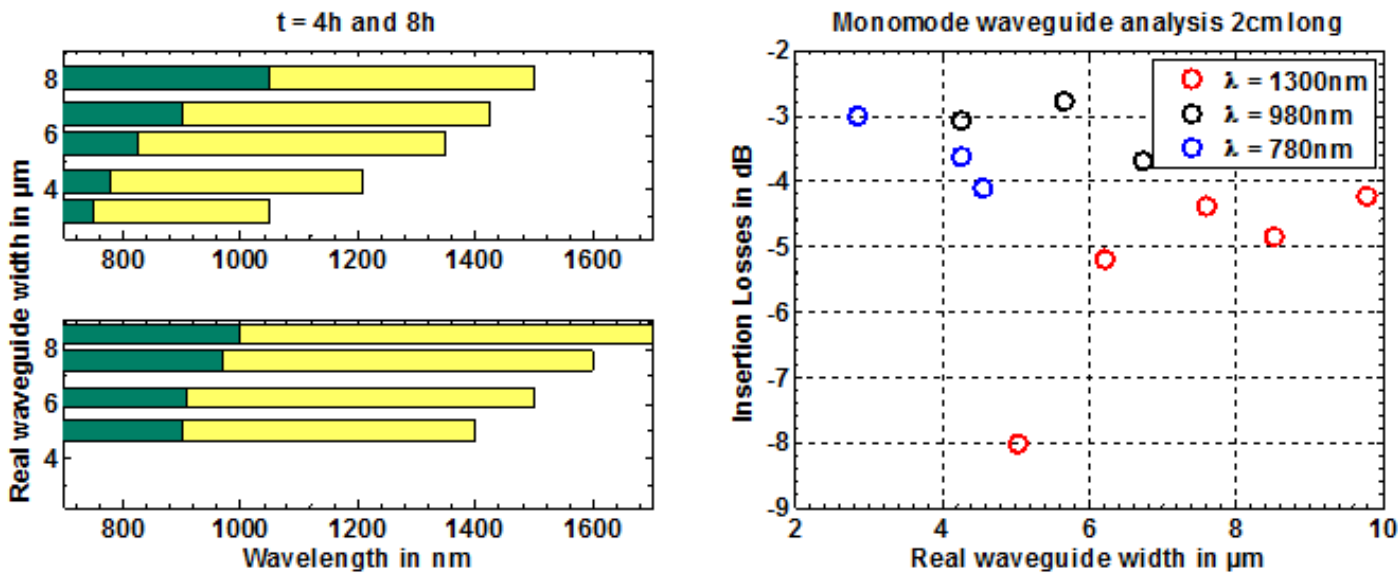

Figure 7. Evolution of the monomodicity zone following the ion-exchanged time and the real waveguide width realized in the soda lime glass. A $780 H P$ single mode is used for $\lambda=780 \mathrm{~nm}$ and a $H I 1060$ single mode fiber is used for $\lambda=980$ and $1300 \mathrm{~nm}$.

$700 \mathrm{~nm}$ to $1700 \mathrm{~nm}$. A step intensity of the signal on the spectrum is related to the apparition of a new mode. The cut-off wavelength of the first and the second modes are shown in the figure 7 . The monomodicity bandwidth measured can be compared to the modelized results shown in figure 3. The model seems to be sufficient to define the time exchanged to use in order to have the right monomode bandwidth.

Finally, the insertion losses have been measured to estimate the propagation losses in this type of waveguide. Insertion losses of $3 \mathrm{~dB}$ has been obtained for $\lambda=980 \mathrm{~nm}$ or $\lambda=780 \mathrm{~nm}$. As the waveguide length is $2 \mathrm{~cm}$, it has an attenuation smaller than $1.5 \mathrm{~dB} / \mathrm{cm}$ if the coupling is considered null. Added measurement with an objective lens instead of the output fiber allows us to estimate the coupling losses around $1 \mathrm{~dB}$ giving an attenuation of $0.5 \mathrm{~dB} / \mathrm{cm}$. But other measurement using the cutt-back method must be used to confirm this value. 


\section{CONCLUSION}

To conclude, we show an easy method to realize $2 \mathrm{D}$ confined waveguide without clean room process. This method can be adapted to all planar waveguide technology. A minimum width of $2.5 \mu \mathrm{m}$ is obtained with this method. The quality and the polishing are enough good to have attenuation estmated to $0.5 \mathrm{~dB} / \mathrm{cm}$.

\section{ACKNOWLEDGEMENT}

The SEM images were taken with the help of CNRS Renatech (PTA) cleanroom in Grenoble. The authors gratefully acknowledge the Agence Nationale de la Recherche for funding support through the grant ANR-16CE39-0016-01.

\section{REFERENCES}

[1] Merzou W.A., Cagneau B., Gardillou F., Hilouane K. and Chassagne L.," Highly compact and easy-to-use optical chip interferometer with picometric performances", AIP Rev. of Sci. Inst., 87, pp. 103103 (2016).

[2] Geoffray G., Allenet T., Canto F., Couston L., Bucci D., Jardinier E. and Broquin J-E.," Development of an opto-fluidic microsystem dedicated to chemical analysis in a nuclear environment", Procedia Chemistry, 21, pp. 453-460 (2016).

[3] Morand A., Warzecha A., Ghibaudo E., Thomas F., Benech P., Le Coarer E., Puget R., Bonneville C., Martin B., Cassagnettes C. and Barbier D. ," A fully static OCT sensor using a glass integrated optic chip bonded to a CCD linear camera", Proc. SPIE, 9365, pp. 93650X (2015).

[4] Duchemin C., Thomas F., Martin B., Morino E., Puget R., Oliveres R., Bonneville C., Gonthiez T. and Valognes N.," Development of an inegrated sub-picometric SWIFTS-based wavelength meter", Proc. SPIE, 10110, pp. 1011016 (2017).

[5] Berger et al," An integrated optics 3 way beam combiner for IOTA", Proc. SPIE, 4838, pp. 1011016 (2002).

[6] Tervonen A., West R. B. and Honkanen S.," Ion-exchanged glass waveguide technology: a review", Opt. Eng. 50, 071107 (2011).

[7] Kufner M. and Kufner S," Ion exchange technology for optical waveguides", Optik \& Photonik, 4, Wiley-VCH Verlag, pp. 32-34 (2011).

[8] Gardillou F.," A little piece of glass can change everything", PIC Magazine, Issue 3, December (2016).

[9] Fuest R., Fabricius N. Hollenbach U. and Wolf B.," Interferometric displacement sensor realized with a planar $3 x 3$ directional coupler in glass", Proc. SPIE, 1794 (1993).

[10] McCourt M.," Commercial glass waveguide devices", Proc. SPIE, 10275 (1994).

[11] Broquin J-E.," Glass integrated optics: state of the art and position toward other technologies", Proc. SPIE 6475, 647507 (2007).

[12] Courjal N., Devaux F., Gerthoffer A., Guyot C., Henrot F., Ndao A., Bernal M-P.," Low-loss LiNbO3 tapered-ridge waveguides made by optical-grade dicing", Opt. Exp. 23, pp. 13983-13990 (2015).

[13] Courjal N., Bernal M-P., Caspar A., Ulliac G., Bassignot F., Gauthier-Manuel L. and Suarez M.," Lithium Niobate Optical Waveguides Microwaveguides", Interchopen books, Emerging Waveguide Tehcnology, Chapter 8 (2018).

[14] Lin A., Lei W., Xintong Z., Chen C. and Feng C.," Depth profile of the nonlinear susceptibility of LiNbO3 ridge waveguides fabricated by ion implantation and dicing", Opt. Mat. Exp., 7, pp. 3836-38043 (2017).

[15] Volk M. F., Rter C.E., Santandrea M., Eigner C. Padberg L., Herrmann H., Silberhorn C. and KIP D.," Fabrication of low-loss Rb-exchanged ridge waveguides in z-cut KTiOPO4", Opt. Mat. Exp., 8, pp. $82(2018)$.

[16] Yao Y., Wang W., Zhang D. and Gao X.," Planar and ridge ZnO optical waveguides produced by $15 \mathrm{MeV}$ C5+ ion irradiation", Opt. Mat. Exp., 5, pp. 1498 (2015).

[17] Bucci D., Martin B. and Morand A.," Application of the three-dimensional aperiodic Fourier modal method using arc elements in curvilinear coordinates", 29, pp. 367-373 (2012)

[18] Bucci D., Martin B. and Morand A., "Study of propagation modes of bent waveguides and micro-ring resonators by means of the aperiodic Fourier modal method", Proc. of SPIE 7597, 75970U (2010). 
[19] Carpenter L. G., Rogers H. L., Cooper P. A., Holmes C., Gates J. C. and Smith P. G. R., "Low optical-loss facet preparation for silica-on-silicon photonics using the ductile dicing regime", IOP J. Phys. D: Appl. Phys., 46, 475103 (2013).

[20] Sane A.J., Cooper A.R.," Stress Building and Relaxation During Ion Exchange Strenghening of Glass", J. Amer. Ceram. Soc., 70, pp. 86-89 (1987). 